\title{
New materials for solid state electrochemistry
}

\section{P. FERLONI and A. MAGISTRIS}

Dipartimento di Chimica Fisica and C.S.T.E.-C.N.R., Università di Pavia, Viale Taramelli 16, 27100 Pavia, Italy

\begin{abstract}
Solid state electrochemistry is an interdisciplinary area, undergoing nowadays a fast development. It is related on the one hand to chemistry, and on the other hand to crystallography, solid state physics and materials science. In this paper structural and electrical properties of some families of new materials interesting for solid state electrochemistry are reviewed.

Attention is focused essentially on ceramic and crystalline materials, glasses and polymers, displaying high ionic conductivity and potentially suitable for various applications in solid state electrochemical devices.
\end{abstract}

\section{Introduction}

Materials with innovative electrical properties, or "advanced materials", have attracted worldwide attention due to their wide spectrum of potential applications, ranging from energy storage to telecommunications, informatics, aircraft and space industry. There is a great need for new materials displaying peculiar electrical properties, in particular, in those European countries which are remarkably dependent on foreign countries for energy resources. Research and development of new materials for applications in the solid state, namely in electrochemistry, will make available new devices with revolutionary properties which are essential for energy saving and for advanced technology.

The present review will focus on materials designed for use in solid state electrochemistry. It is well known that galvanic cells can be assembled with solid materials just as with liquid ones.

Major disadvantages of electrochemical systems incorporating liquid components are:

- leakage and spillage, leading to possible loss of electrolyte and to corrosion phenomena;

- lack of mechanical integrity in the system formed by electrodes and electrolyte, which is relatively fragile. Incorporation of the liquid within a suitable matrix in solid, semi-solid, or gel state has been the main contrivance for overcoming these difficulties.

In solid state devices, on the contrary:

- convection is absent, diffusion and conduction are relatively slow processes, especially at room temperature;

- the solid electrolyte may exist in many states and take very different shapes, like a thin film of glass or polymer, a pellet of a compacted powder, a slice of a single crystal. 
For sake of completeness, one should also mention the following handicaps of solid state electrochemical devices:

- high ohmic drop within the electrolyte;

- limited transport of reactants and products to and from the interphases;

- poor contacts at the electrode-electrolyte interfaces, because of the rough state of the surfaces involved;

- modest ability to adapt to dimensional changes occurring during charge-discharge processes, leading to loss of electrical contact between electrode and electrolyte and to possible cell rupture.

Conversely, solid electrochemical cells are easy to construct in a compact form, leak-proof and robust. These advantages make them suitable for a wide range of special purposes and applications, which will be discussed below with the aid of selected examples.

In this review, after some general comments on conduction in solids, and on the experimental techniques suitable for carrying out investigations in solid state electrochemistry, we shall consider widely different materials like inorganic salts, ceramic oxides, and polyethers.

\section{General considerations}

Two general questions should be considered in discussing ionic conduction in solids:

- how can a solid be an ionic conductor, and how large can this ionic conduction become?

- which applications are open to solid conductors in electrochemical science and technology?

The first question leads one to discuss disorder in solids. One limiting case is structural disorder - the quasi molten state - of a partial lattice of a crystalline substance. This explains how conduction in some solid electrolytes can become as high as in concentrated aqueous solutions or molten salts.

The second set of questions addresses scientific and technological applications. Solid electrolytes can be used for many different purposes, including the following ones:

- batteries and fuel cells

- sensors

- display units

- electrochromic devices

- thermodynamic and kinetic investigations.

For further information, the reader is referred to introductory textbooks 1,2 , and to various reviews and conference proceedings ${ }^{3,4}$.

Three families of materials have recently attracted attention of researchers and interest of technicians who design solid state electrochemical devices:

- crystals and ceramics

- ionically conductive glasses

- conductive polymers.

Among the many materials one can find in these three general groups, those which deserve attention not only correspond to peculiar chemical compositions, but also display characteristic electrochemical behaviour associated with various properties making them interesting for possible applications, such as transparency and optical quality, flexibility and mechanical resistance, plasticity, durability, thermal and chemical stability. 
From the standpoint of the useful temperature range in which solid ionic conductors can work, they can be classified as:

- materials for room and low-medium temperature devices, such as $\mathrm{RbAg}_{4} \mathrm{I}_{5}, \beta$-alumina, doped polyethers, inorganic glasses; ceramics;

- materials for systems operating at medium-high temperature, e.g. glasses, Bi oxide-based conductors.

- materials for high temperature applications, such as stabilized zirconia and other anionic

Figure 1 illustrates the conductivities of some important solid electrolytes as a function of the reciprocal temperature, without any claim of completeness, if only because new electrolytes are currently being reported weekly. The conductivity of concentrated sulfuric acid is included for comparison. It can be remarked that conductivities of solid electrolytes lie in the same range as that of concentrated liquid electrolytes.

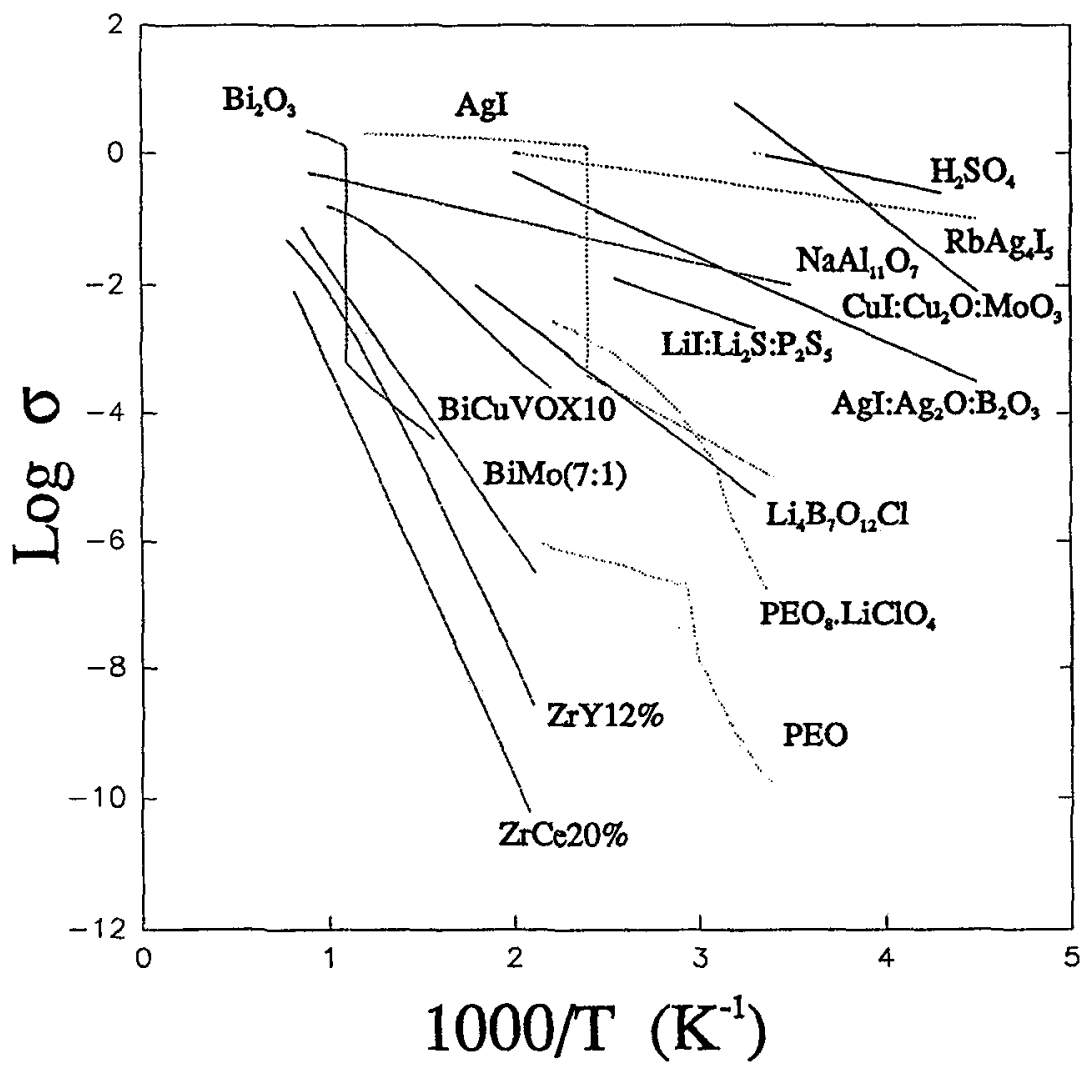

Figure 1. Conductivities of important solid electrolytes as a function of the reciprocal temperature. 
Before discussing in detail some examples of new materials for solid state elctrochemistry, some physical techniques adopted for these studies seem worthy of mention. Besides classical methods for solid state studies, like thermal, optical, spectroscopic techniques, optical and electronic microscopy, techniques for surface studies, X-ray diffraction, and many other techniques for which the reader is referred to a comprehensive review ${ }^{5}$, the fundamental technique employed in studies of solid state electrolytes is impedance spectroscopy ${ }^{6}$.

The main advantage of this technique consists in the possibility of separating the contribution of processes taking place within the electrolyte from those arising from electrode polarization. The analysis of the frequency data is performed on the basis of an appropriate model representing the cell under investigation. Usually, a simple and suitable way to study the properties of electrodes and electrolyte involves the choice of an equivalent electrical circuit worked out taking into account the main physical processes occurring in the cell.

Bauerle $^{7}$ in 1969 was the first to apply this method to analyze the frequency response of an electrochemical cell of the following type:

$$
\text { Air, } \mathrm{Pt} / \mathrm{ZrO}_{2}: \mathrm{Y}_{2} \mathrm{O}_{3} / \mathrm{Pt} \text {, Air }
$$

The equivalent circuit of this cell is illustrated in the scheme of figure 2, where the impedance $Z$ is represented in the complex plane $\operatorname{Im}(Z)$ vs $\operatorname{Re}\{Z\}$.

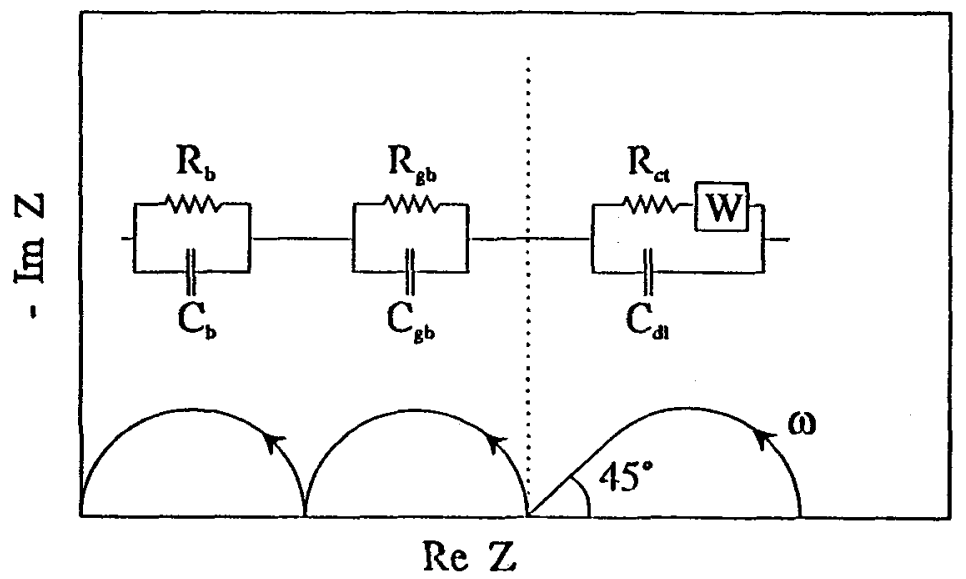

Figure 2. Equivalent circuit and impedance diagram for a cell with a solid polycrystalline electrolyte.

Three arcs are observed, and they are interpreted as follows:

- a) the arc appearing at lower frequency is due to the processes occurring at the electrodeelectrolyte interface. It represents the charge transfer resistance, $R_{c t}$, in parallel with the double layer capacity, $\mathrm{C}_{\mathrm{dl}}$. When the kinetics of the electrode reaction is controlled by diffusion of a reactive species, a straight line with a slope of $45^{\circ}$ is shown, corresponding to the Warburg impedance $Z_{w}$;

- b) the processes taking place within the electrolyte are represented by two arcs describing, at higher frequencies, the parallel circuit made of resistance and geometrical capacity of the electrolyte, $R_{b}$ and $C_{b}$, and at intermediate frequencies the parallel circuit assembling resistance and capacity of grain boundaries, $\mathrm{R}_{\mathrm{gb}}$ and $\mathrm{C}_{\mathrm{gb}}$. A slightly different model was suggested in a discussion of the method worked out by Schouler and coworkers 8 . 
A similar analysis can be successfully applied to the description of various materials, like glasses, composites and polymers, as well as to the characterization of electrochemical devices.

\section{Ceramics and crystals}

Silver and lithium iodides and related salts - AgI forms the basis of a large family of silver ion conductors displaying the highest known ionic conductivity in the solid state at low temperature. Tubandt and Lorenz ${ }^{9}$ were the first to observe at $146^{\circ} \mathrm{C}$ the phase transition $\beta-->\alpha$ from the wurtzite-type to the body centred cubic structure, which has a conductivity of $1.31 \Omega^{-1} \mathrm{~cm}^{-1}$ at the transition temperature.

In an attempt to stabilize the high conductivity $\alpha$-phase of $\mathrm{AgI}$ at ambient temperature, many structural modification have been tried. The best known material is the cation substituted compound $\mathrm{RbAg}_{4} \mathrm{I}_{5}$, discovered by Bradley and Greene ${ }^{10}$, and independently by Owens and Argue $^{11}$. This salt has found application in button-type batteries. On the other hand, the $\mathrm{Li} / \mathrm{I}_{2}$ pacemaker battery has been the most successful commercial solid state cell ${ }^{12}$.

Various types of batteries developed during the past forty years, making use of these solid electrolytes, have been presented in a recent review ${ }^{13}$. In figure 3 the conductivities of these silver salts are illustrated, together with those of sulphuric acid and $\beta$-alumina.

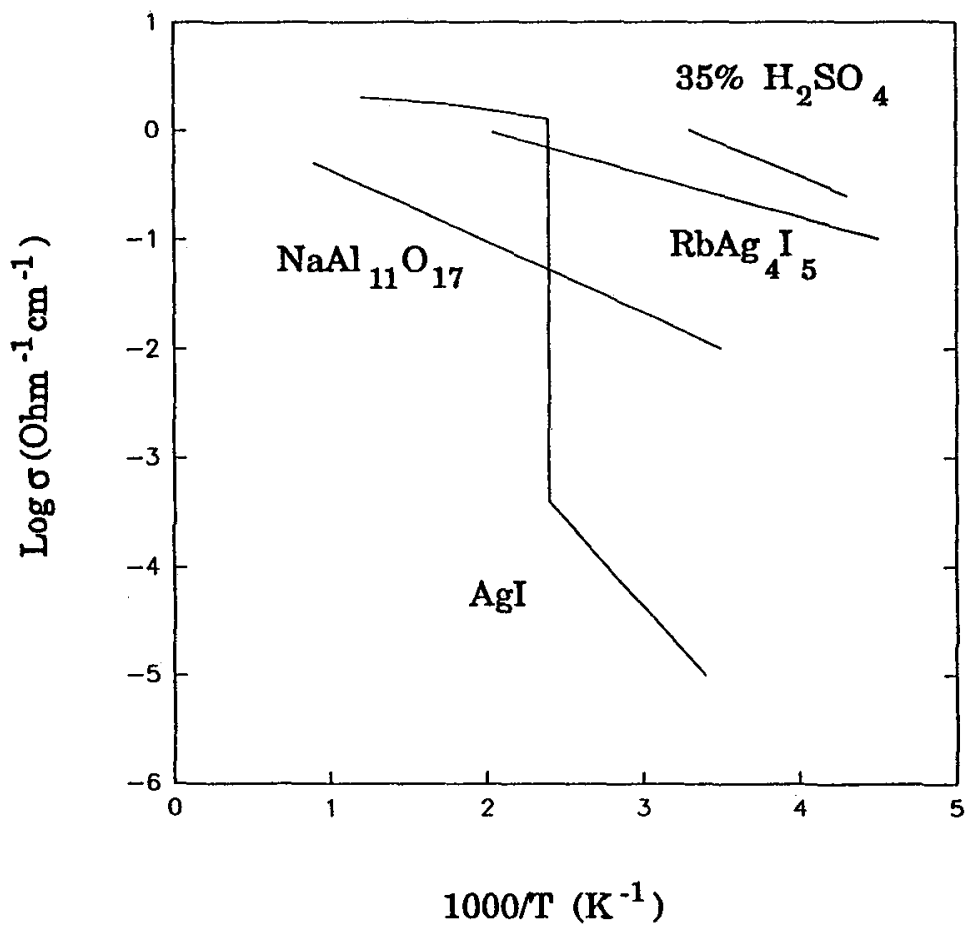

Figure 3. Conductivities of some crystalline electrolytes. 
$\beta$-alumina and $\beta$ "-alumina - Yao and Kummer's observation 14 that sodium beta-alumina has a $\mathrm{Na}^{+}$ion conductivity at room temperature comparable to that of aqueous $\mathrm{NaCl}$ stimulated widespread interest in the topic of fast iontransport in $\beta$-aluminas and led to extensive efforts to develop the sodium/beta-alumina/sulfur battery.

Sodium $\beta$-alumina is a $\mathrm{Na}^{+}$conductor with a stoichiometric formula $\mathrm{NaAl}_{11} \mathrm{O}_{17}$, more generally expressed as $\mathrm{Na}_{2} \mathrm{O} .11 \mathrm{Al}_{2} \mathrm{O}_{3}$. The crystal structure is hexagonal, with a layered formation perpendicular to the $c$-axis consisting of blocks of aluminium and oxygen ions in a spinel-like configuration and interspersed by layers containing $\mathrm{Na}^{+}$and $\mathrm{O}^{--}$ions only. Spacings of $11.3 \AA$ between spinel blocks allow easy motion of the $\mathrm{Na}^{+}$ions in two dimensions within the layer, whereas no motion is possible in the $c$-axis direction.

Sodium $\beta^{\prime \prime}$-alumina, with the general formula $\mathrm{Na}_{1+\mathrm{x}} \mathrm{Mg}_{\mathrm{x}} \mathrm{Al}_{11-\mathrm{x}} \mathrm{O}_{17}$, in which $\mathrm{x} \sim 0.67$, has a higher electrical conductivity, but lower mechanical strength than the $\beta$ phase. Perhaps the most interesting property of $\mathrm{Na} \beta^{\prime \prime}$-alumina is its ability to undergo rapid ion exchange reactions in which sodium is replaced by a wide variety of mono-, di- and trivalent cations 15,16 . Some of these new materials have possible applications not only as solid electrolytes, but also in optics as solid state laser hosts ${ }^{17}$.

A sodium-sulfur cell was first described by Kummer and Weber ${ }^{18}$. It basically consists of a molten $\mathrm{Na}^{+}$anode and a cathode of graphite impregnated with molten sulfur, separated by a $\beta$ alumina electrolyte. The $\beta$-alumina is often fabricated in the form of a closed-end tube which acts as a container for the sodium anode, and is immersed in the cathode compartment. A comprehensive description of various types of sodium-sulfur batteries can be found in ref. 19 .

Oxides with fluorite structure - Among early researches on solid electrolytes, Nernst's work on a high-temperature cell based on a $\mathrm{ZrO}_{2}\left(\mathrm{Y}_{2} \mathrm{O}_{3}\right)$ solid solution can be mentioned ${ }^{20}$ and a fuel cell using this oxide electrolyte was first constructed in $1937^{21}$. Afterwards, many experimental data were collected concerning the high mobility of oxygen ions in solid solutions based on zirconia. However, more intense interest in the oxide electrolytes was aroused by the classic works of Kiukkola and Wagner ${ }^{22}$, especially in view of adopting these materials as electrolytes in solid oxide fuel cells (SOFC).

Among the materials used in SOFCs, the best known and most thoroughly investigated oxides with high $\mathrm{O}^{--}$conductivity are those with $\mathrm{CaF}_{2}$ and fluorite-related structure, like $\mathrm{ZrO}_{2}$, in which high concentrations of oxygen vacancies are introduced by substitutional dissolution of lower valent cations, like $\mathrm{Ca}^{++}$, or $\mathrm{Y}^{3+}$. The fluorite structure is a face-centred cubic arrangement of cations with the anions occupying all the tetrahedral sites. Each metal cation is surrounded by eight oxygen anions, and each oxygen anion is tetrahedrally coordinated with four metal cations. Having a large number of octahedral interstitial voids, this structure is a rather open one, and it is suitable for fast oxygen ion diffusion at high temperatures 23 . The doping agent plays also the role of stabilizing the fluorite structure which, e.g. in pure $\mathrm{ZrO}_{2}$, at lower temperatures might undergo a transition to a non conductive monoclinic phase. In figure 4 the conductivities of some ceramic oxide electrolytes are compared.

Electrical and mechanical properties of these solid solutions are the subject of both fundamental and applied investigations, not only in high temperature research ${ }^{24}$, or in development of gas sensors (see, e.g., a recent review ${ }^{25}$ ), but especially for SOFCs operating at $700-1000^{\circ} \mathrm{C}$. If compared with other types of fuel cells, SOFCs display advantages such as a good long-range stability, a high energy conversion factor, and a limited electrode polarization, due to the high working temperature, as well as the absence of liquid phases ${ }^{26}$. 


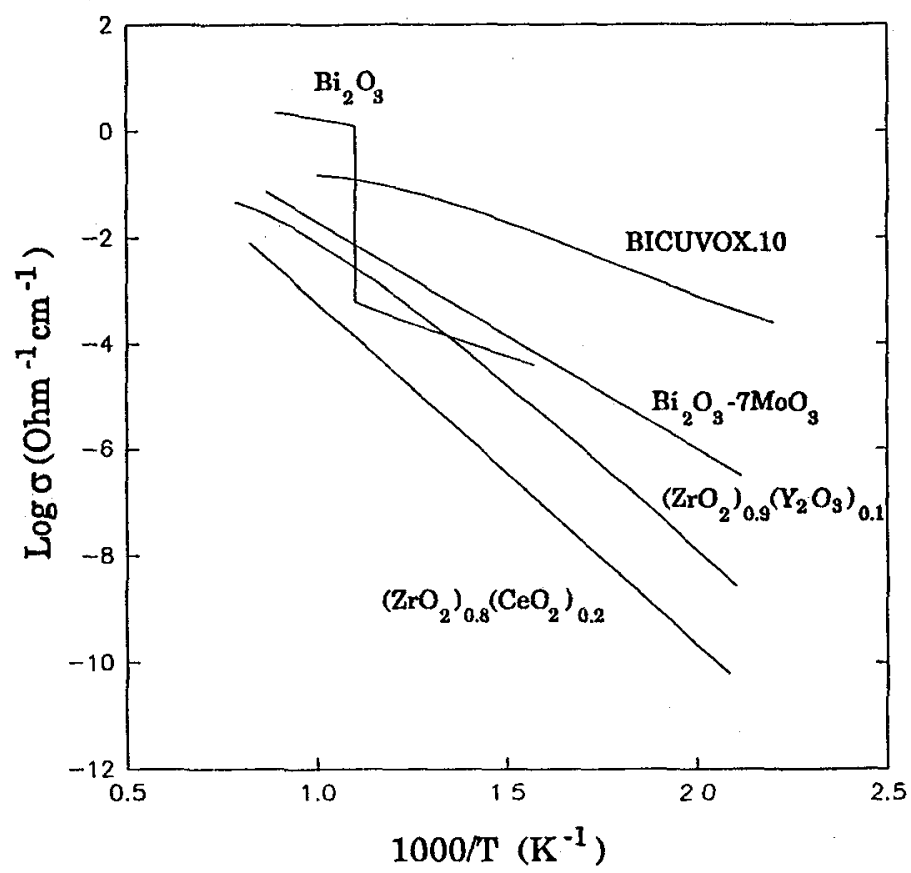

Figure 4. Conductivities of some ceramic oxide electrolytes.

The fact that new electrode materials are under investigation in order to replace expensive metals, like Pt, on a large scale, is perhaps also worthy of mention. Thus, the need for low-cost electrodes in industry has promoted active research on other materials, such as $\mathrm{La}_{1-x} \mathrm{Sr}_{\mathbf{x}} \mathrm{MnO}_{3}$, which is able to display an electrochemical activity comparable to that of the noble metals 27 .

From the standpoint of technology, an important goal is to decrease the working temperature of these electrochemical devices. A promising material is $\mathrm{Bi}_{2} \mathrm{O}_{3}$, which exhibits a highly conductive, disordered, $\delta$ phase which is stable above $730^{\circ} \mathrm{C}$. In order to stabilize this phase at lower temperatures, di-, tri-, penta-, and hexavalent metal oxides have been successfully introduced into the lattice of $\mathrm{Bi}_{2} \mathrm{O}_{3}$, producing, however, metastable phases. Recently, a new family of high performances conductors, derived from $\mathrm{Bi}_{2} \mathrm{~V}_{4} \mathrm{O}_{11}$ by partial substitution of $\mathrm{V}$ by other metal ions ("BIMEVOX") has been proposed 28 .

\section{Glasses}

Transport of sodium ion through Thuringer glass was already observed in 1884 by Warburg ${ }^{29}$. Some further work was carried out on glass electrodes and sodium conducting glasses in thermochemical cells during the first decade of this century. However, a common characteristic of those glasses was their relatively high electrical resistivity.

The possibility of producing glassy mixtures exhibiting high ionic conductivity was first mentioned at the Belgirate meeting on fast ion transport in solids in 1972 by Kunze ${ }^{30}$. At the same time, systematic investigations on a wide family of glassy electrolytes containing $\mathrm{AgI}$ and $\mathrm{Ag}_{\mathrm{n}} \mathrm{XY}_{4}$, where $\mathrm{XY}_{4}$ are anions with tetrahedral configuration, were undertaken by our group. The possibility of obtaining at ambient temperature glassy phases with high mobility of the $\mathrm{Ag}^{+}$ion, comparable 
with that of the above mentioned $\alpha$-Agl phase, stable above $146^{\circ} \mathrm{C}$, was suggested 31 . Since these early studies, many experimental results have been reported, and reviews have been published 32,33 .

Because of the interest in high energy density batteries, there have been numerous attempts to develop lithium and sodium fast ionic conductors (FIC) in the glassy state. The best conductors are lithium borate glasses doped with lithium halides ${ }^{34}$, which exhibit conductivities ranging between $10^{-3}$ and $10^{-2} \Omega^{-1} \mathrm{~cm}^{-1}$ at $300^{\circ} \mathrm{C}$.

It was also realized that the substitution of the oxygen ion with a larger, more polarizable, glass forming ion, such as $\mathrm{S}^{--}$, would increase ionic conductivity in inorganic glasses. Actually, sulphide glasses are among the best $\mathrm{Li}^{+}$and $\mathrm{Na}^{+}$conductors at room temperature ${ }^{35-38}$. Recently, $\mathrm{Cu}^{+}$ion conducting glasses have been also reported ${ }^{39}$. Data concerning the lithium chalcogenide conductive glasses are given in ref. 40 . In figure 5, the conductivities of some glassy electrolytes are compared.

In a study on the silver borophosphate glasses 41 , it has been observed that ionic conductivity passes through a maximum when the $\mathrm{P}_{2} \mathrm{O}_{5}$ was substituted for $\mathrm{B}_{2} \mathrm{O}_{3}$. This phenomenon, known as mixed-former effect, occurs in many conductive glasses, like borophosphates, borosilicates and chloroborates, i.e. multi-component systems in which a co-glass former has been added to enhance conductivity.

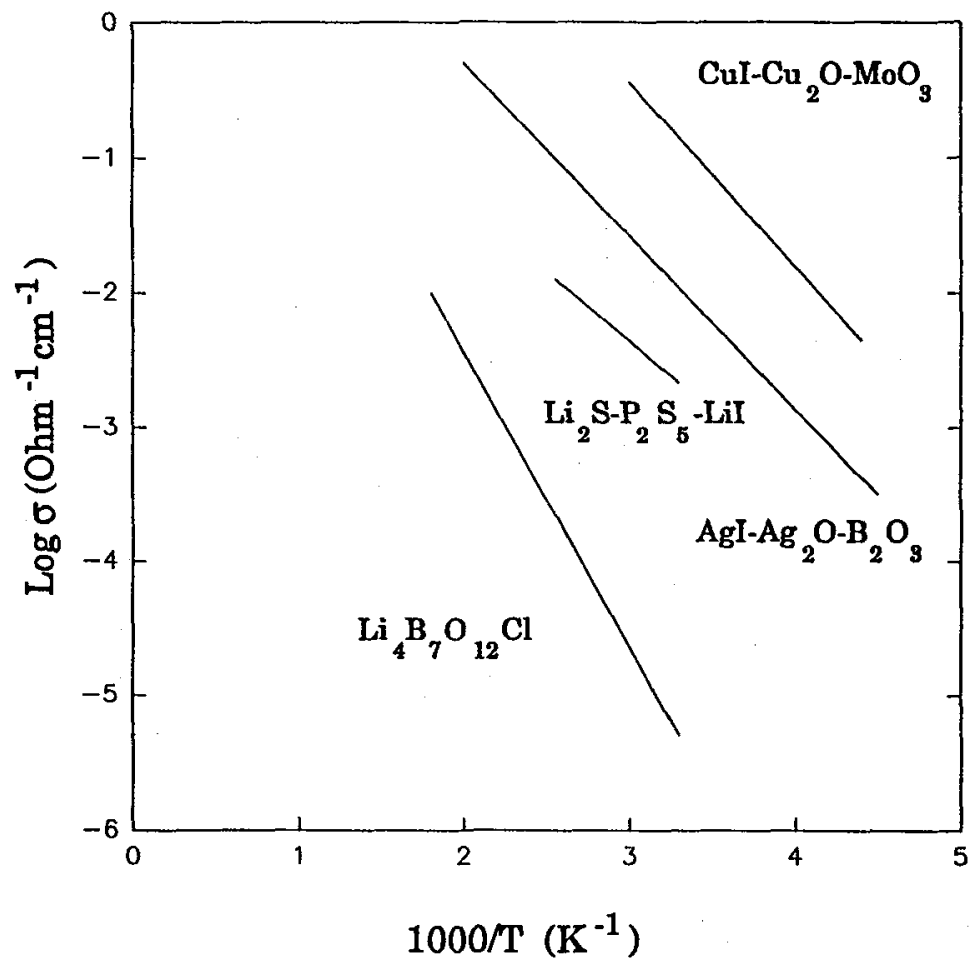

Figure 5. Conductivities of some glassy electrolytes. 
The problem of modeling ionic conductivity, $\sigma=\mathrm{Zen} \mu$, where $\mathrm{Ze}$ is the charge of the conducting ion, $\mathrm{n}$ the concentration, and $\mu$ the mobility, is that of evaluating the influence of both terms. The most often recurring models are the classical Anderson-Stuart approach ${ }^{42}$ and the weak electrolyte theory. According to the latter, developed by Ravaine and Souque ${ }^{43}$, the treatment applied to glasses is similar to the familiar theory of conduction in aqueous dilute solutions, and the variation in equivalent conductivity on dilution is explained only by a small and variable degree of dissociation, and only a small fraction of the ions is contributing, at a given time, to the conduction. The change in conductivity with the concentration of the charge carrier is proportional to the square root of its activity. Thus, the theory proposes that the major effects of composition changes on conductivity occur via variations in carrier concentration.

Glassy electrolytes offer many advantages, such as homogeneity, absence of grain boundaries, ease of preparation of thin films with large surface area, wide composition ranges, transparency. New potential applications include batteries ${ }^{44}$, electrochromic displays, smart windows, chemical and electrochemical sensors. One of the most interesting features of glass-based devices is that they can be miniaturized, and therefore adapted to be used in microelectronics ${ }^{45}$.

\section{Polymers}

Polymers were normally thought of as electrical insulators, and they found extensive application in insulating systems. Electrical conduction in polymers was regarded as an undesirable phenomenon causing breakdown in polymer based insulators. By the end of the seventies, however, a rapidly growing and changing area has developed, starting from the opposite standpoint, that is considering certain polymers as materials which are able to conduct electricity, either by means of ions, or by electrons. Electronically conductive polymers will not be discussed here: the interested reader is referred to a recent review covering some aspects of this field ${ }^{46}$.

After earlier isolated works had pointed out the existence of certain polyether-inorganic salt complexes, a pioneering paper by Armand, Chabagno and Duclot ${ }^{47}$ showed that polyethers can act as suitable solid solvents for a variety of inorganic salts. Complexes formed, in particular, between poly(ethylene oxide) $[\mathrm{P}(\mathrm{EO})]$, or poly (propylene oxide) $[\mathrm{P}(\mathrm{PO})]$ and lithium salts were proposed as potentially interesting electrolytes for solid state batteries. Two review books are already available, in which main recent studies on the properties of these new materials have been summarized 48 .

The increase in conductivity which is associated to melting of $P(E O)$ suggested that ionic motion in the molten, elastomeric phase is easier than in the crystalline one. It was recognized that ionic conductivity in the doped $\mathrm{P}(\mathrm{EO})$ takes place mainly in the amorphous phase ${ }^{47,49}$. In fully amorphous, elastomeric materials, conductivity is higher and follows a free-volume regime described by the Vogel-Tamman-Fulcher law:

$$
\sigma=\sigma_{0} \exp \frac{-E_{a}}{R\left(T-T_{0}\right)},
$$

where $\mathrm{T}_{0}$ is the "ideal" glass transition temperature, and $\mathrm{T}-\mathrm{T}_{0}$ is the basic parameter determining the free volume fraction and the viscoelastic response of the material. On the other hand, mixed amorphous-crystalline phases with much lower conductivity show the classical Arrhenius behaviour.

With the purpose of characterizing the interactions between poly(ethylene oxide) and the doping inorganic salts, extensive investigations of phase diagrams were undertaken, in spite of the 
fact that in the pure polymer, as well as in its mixtures with salts, the coexistence of the amorphous, metastable, phase with one or more crystalline, stable, phases prevents a direct application of the Gibbs phase rule. Among the phase diagrams reported in the recent literature, the most frequently cited ones, i.e. those formed with $\mathrm{P}(\mathrm{EO})$ and lithium salts, may deserve mention ${ }^{50}$. In some of these diagrams, the temporary existence of fully amorphous phases within certain temperature and composition ranges was brought out ${ }^{50 \mathrm{c}, \mathrm{e}}$.

An attractive way of enhancing ionic conductivity could be the introduction of crosslinks into the amorphous phase of $\mathrm{P}(\mathrm{EO})-\mathrm{MX}$ electrolytes, in order to hinder crystallization ${ }^{51}$. This goal has been atrained, e.g., by means of a chemical method making use of the reaction of low-molecular weight $\mathrm{P}(\mathrm{EO})$ with isocyanates ${ }^{52}$, or by irradiating with $\gamma$-rays aqueous solutions of the pure and doped polymer ${ }^{53}$. Crosslinks between polyether chains are also established when the polymer is doped with, e. g., a divalent metal salt. In this case a predominantly anionic conduction can be expected. Many $\mathrm{P}(\mathrm{EO})$ based electrolytes containing divalent or trivalent cations have been characterized. In a recent review a discussion of their structural and electrical properties is summarized ${ }^{54}$.

A comparison of ionic conductivities of several $\mathrm{P}(\mathrm{EO})$-based polymer electrolytes is illustrated in figure 6. For all the considered materials, a fairly good conductivity is reached at about $60^{\circ} \mathrm{C}$, and it may be noticed that $\mathrm{P}(\mathrm{EO})_{8} \cdot \mathrm{Cu}\left(\mathrm{ClO}_{4}\right)_{2}$ displays a relatively high conductivity around room temperature.

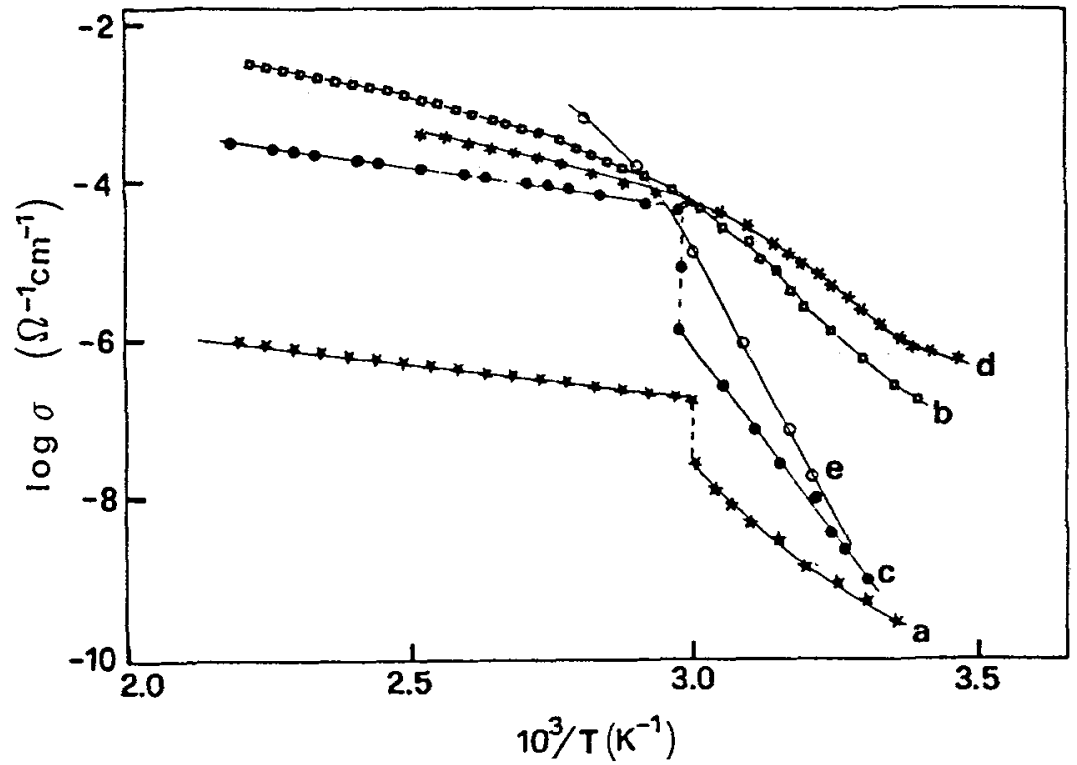

Figure 6. Conductivities of $\mathrm{P}(\mathrm{EO})$-based polymer electrolytes containing different perchlorates. a) $\mathrm{P}(\mathrm{EO})$; b) $\mathrm{P}(\mathrm{EO})_{8} \cdot \mathrm{LiClO}_{4}$; c) $\mathrm{P}(\mathrm{EO})_{20} \cdot \mathrm{Pb}\left(\mathrm{ClO}_{4}\right)_{2}$; d) $\mathrm{P}(\mathrm{EO})_{8} \cdot \mathrm{Cu}\left(\mathrm{ClO}_{4}\right)_{2}$; e) $\mathrm{P}(\mathrm{EO})_{20} \cdot \mathrm{Hg}\left(\mathrm{ClO}_{4}\right)_{2}$. 
Many different new polymers have been recently designed and tested. Various uncommon $P(E O)$ structures, such as comb-shaped polyvinylethers, or new host networks modified with plasticizers, have been considered. The "third generation" of polymer electrolytes includes materials formed by trapping a low molecular weight liquid solution of a lithium salt in an aprotic organic solvent within the polymer matrix of a high molecular weight material. On films of the latter type, higher conductivities, of the order of $10^{-3} \Omega^{-1} \mathrm{~cm}^{-1}$, have been measured at room temperature ${ }^{13}$.

It should finally be mentioned that important efforts for practical applications of solid polymer electrolytes in batteries are in progress. Major development programmes for polymer electrolyte/lithium batteries have been reported by a number of laboratories, including Harwell (UK), HydroQuebec (Canada), and the L.I.E.S.G.-E.N.S.E.E.G. in Grenoble (F). A review describing some interesting results of the French-Canadian cooperation in this area is available 55 .

\section{Conclusions}

Some families of new materials recently characterized from the standpoint of solid state electrochemistry have been briefly mentioned. Much work remains to be made for a better characterization of these materials in view of practical applications, as well as for a deeper understanding of their physical and chemical properties. Of course, there is little hope of discovering new exceptional ionic conductors in the near future.

However, the need for finding out different new materials, in which good electrochemical properties may be associated with other physical properties interesting from the viewpoint of technology, is promoting creative endeavour in the area of solid state electrochemistry. Composite materials, heterogeneous, colloidal or dispersed systems, like liquids trapped in solid matrices, can be invented and optimized. Other disciplines, such as organic chemistry, microelectronics, applied optics, solid state physics, polymer science, may play a significant role in this area. Angell has recently given a hint to the opportunities offered by matching polymer science and inorganic chemistry 56 .

\section{References}

1. F. A. Kröger, The Chemistry of Imperfect Crystals, 3 Vols., North Holland, Amsterdam (1973)

2. C. Deportes, Ed.: Electrochimie du solide, Grenoble (1993) in press

3. C. A. C. Sequeira, A. Hooper, Eds.: Solid State Batteries, NATO ASI Series, Series E, Applied Sciences n. 101, Martinus Nijhoff Publ., Dordrecht, NL (1985)

4. a) B. V. R. Chowdari and S. Radhakrishna Eds.: Solid State Ionic Devices, World Scientific Publ., Singapore (1988); b) B. V. R. Chowdari, S. Chandra, Shri Sing, P. C. Srivastava Eds.: Solid State Ionics: Materials and Applications, World Scientific Publ., Singapore (1992)

5. R. G. Linford, S. Hackwood, Chem. Rev. 81 (1981) 327

6. J. Ross Macdonald, Ed.: Impedance Spectroscopy, J. Wiley, New York (1987)

7. J. E. Bauerle, J. Phys. Chem. Solids 30 (1969) 2657

8. E. J. L. Schouler, G. Giroud, M. Kleitz, J. Chim. Phys. 70 (1973) 1309

9. C. Tubandt, E. Lorenz, Z. Physik. Chem. 87 (1914) 513

10. J. N. Bradley, P. D. Greene, Trans. Fadaray Soc. 62 (1967) 424

11. B. B. Owens, G. R. Argue, Science 157 (1967) 308

12. J. P. Gabano, Ed.: Lithium Batteries, Academic Press, London (1983)

13. B. B. Owens, P. M. Skarstad, Solid State Ionics 53-56 (1992) 665

14. Y. F. Y.Yao, J. T. Kummer, J. Inorg. Nucl. Chem. 29 (1967) 2453

15. G. C. Farrington, B. Dunn, Solid State Ionics 7 (1982) 267 
16. G. S. Rohrer, G. C. Farrington, J. Solid State Chem. 85 (1990) 299

17. G. C. Farrington, B. Dunn, J. O. Thomas, Crys. Lattice Defects Amorph. Mater.12 (1985) 497

18. J. T, Kummer, N. Weber, Proc. Power Sources Conf. 21 (1967) 37

19. J. L. Sudworth, A. R. Tilley, The Sodium-Sulfur Battery, Chapman \& Hall, London (1985)

20. W. Nernst, Z. Elektrochem. 6 (1899) 41

21. E. Baur, H. Preis, Z. Elektrochem. 43 (1937) 727

22. a) K. Kiukkola, C. Wagner, J. Electrochem. Soc. 104 (1957) 308; b) ibid., 379

23. J. A. Kilner, B. C. H. Steele, in $\varnothing$. Toft Sorensen, Ed.: Nonstoichiometric Oxides, Academic Press, London (1981) 233

24. a) T. H. Etsell, S. N. Flengas, Chem. Rev. 70 (1970) 339; b) W. L. Worrell, Am. Ceram. Bull. 53 (1974) 425

25. A. M. Azad, S. A. Akbar, S. G. Mhaisalkar, L. D. Birkefeld, K. S. Goto, J. Electrochem. Soc. 139 (1992) 3690

26. A. Hammou, "High Temperature Fuel Cells", in ref. 4a, p. 243

27. A. Hammouche, A. Caneiro, E. Siebert, A. Hammou, M. Kleitz, J. Electrochem. Soc. (1992)

28. F. Abraham, J, C. Boivin, G. Mairesse, G. Nowogrocki, Solid State Ionics 40-41 (1990) 934

29. G. Warburg, Ann. Phys, 21 (1884) 622

30. D. Kunze, in W. Van Gool, Ed.: Fast Ion Transport in Solids, North Holland, Amsterdam (1973) 405

31. G. Chiodelli, A. Magistris, A. Schiraldi, Electrochimica Acta, 19 (1974) 655

32. C. A. Angell, Solid State Ionics 18-19 (1986) 72

33. J. Kawamura. M. Shimoji, Mater. Chem. and Phys. 23 (1989) 99

34. D. P. Buttom. R. P. Tandon, H. L. Tuller, D. R. Uhlmann, Solid State Ionics 5 (1981) 655

35. A. Levasseur, R. Olazcuaga, M. Kbala, M. Zahir, P. Hagenmuller, C. R. Acad. Sci. Paris 293, ser. II (1981) 563

36. J. P. Malugani, B. Fays, R. Mercier, G. Robert, Solid State Ionics 9-10 (1983) 659

37. A. Pradel, M. Ribes, Solid State Ionics 18-19 (1986) 351

38. J. Kennedy, Y. Yang, Solid State Chem. 69 (1987) 252

39. N. Machida, T. Minami, J. Am. Ceram. Soc. 71 (1988) 784

40. A. Pradel, M. Ribes, Mater. Chem. Phys. 23 (1989) 121

41. A. Magistris, G. Chiodelli, M. Duclot, Solid State lonics 9-10 (1983) 611

42. O. L. Anderson, V. A. Stuart, J. Am. Ceram. Soc. 37 (1954) 573

43. a) D. Ravaine, J. L. Souquet, Phys. Chem. Glasses 18 (1977) 27; b) ibid. 19 (1978) 115

44. H. L. Tuller, M. W. Barsoum, J. Non-Cryst. Solids 73 (1985) 331

45. M. Ribes, V. Delord, in ref $4 a$, p. 147

46. A. G. MacDiarmid, M. R. Maxfield, in R. G. Linford, Ed.: Electrochemical Science and Technology of Polymers, Elsevier Applied Science, London (1987) 67

47. M. Armand, G. Chabagno, M. Duclot, in Vashishta, Mundy, Shenoy, Eds.: Fast Ion Transport in Solids, Elsevier, North Holland (1979) 131

48. a) J. R. MacCallum, C. A. Vincent, Polymer Electrolyte Reviews 1, Elsevier Applied Science, London (1987); b) ibid., 2 (1989)

49. a) J. E. Weston, B. C. H. Steele, Solid State lonics 2 (1981) 347; b) ibid. 7 (1982) 81

50. a) P. R. Sorensen, T. Jacobsen, Polym. Bull. 9 (1983) 47; b) C. D. Robitaille, D. Fauteux, J. Electrochem. Soc. 133 (1986) 515; c) P. Ferloni, G. Chiodelli, A. Magistris, M. Sanesi, Solid State Ionics 18-19 (1986) 265; d) W. Gorecki, R. Andreani, C. Berthier, M. Armand, M. Mali, J. Roos, D. Brinkmann, ibid. 18-19 (1986) 295; e) G. Chiodelli, P. Ferloni, A. Magistris, M. Sanesi, ibid. 28-30 (1988) 1009; f) P. W. M. Jacobs, J. W. Lorimer, A. Russer, M. Wasucionek, J. Power Sources 26 (1989) 503

51. a) H. Cheradame, J. L. Souquet, J. M. Latour, Mat. Res. Bull. 15 (1980) 1173; b) D. F. Shriver, B. L. Papke, M. A. Ratner, R. Dupon, T. Wong, M. Brodwin, Solid State Ionics 5 (1981) 83

52. A. Killis, J. F. LeNest, H. Cheradame, A. Gandini, Makromol. Chem. 183 (1982) 2835 
53. a) R. J. Neat, E. Kronfli, K. V. Lovell, in B. Scrosati, Ed.: Proc. 2nd Int. Symposium on Polymer Electrolytes, Elsevier, London (1990) 151; b) P. Ferloni, A. Magistris, G. Chiodelli, A. Faucitano, A. Buttafava, Radiat. Phys. Chem. 37 (1991) 615

54. G. C. Farrington, R. G. Linford, Poly(ethylene oxide) Electrolytes Containing Divalent Cations, in ref. $47 \mathrm{~b}$, p. 255

55. M. Gauthier, A. Bélanger, B. Kapfer, G. Vassort, M. Armand, "Solid Polymer Electrolyte Lithium Batteries", in ref. $47 \mathrm{~b}$, p. 285

56. C. A. Angell, C. Liu, E. Sanchez, Nature 362 (1993) 137. 